\title{
PENINGKATAN PENDAPATAN PETANI MELALUI USAHA TANAMAN BUAH DAN JAMUR TIRAM DI LAHAN PEKARANGAN MASYARAKAT DESA BEBIDAS KABUPATEN LOMBOK TIMUR
}

\section{Increasing Farmer Income Through Fruit and Mushroom Plant in home-based Land in Bebidas Village East Lombok District}

\author{
Candra Ayu, Wuryantoro* \\ *Program Studi Agribisnis Fakutas Pertanian Universitas Mataram \\ Jalan Majapahit Nomor 62, Kota Mataram \\ *Alamat korespondensi : wuryantorow@yahoo.com \\ (Tanggal Submission: 16 Juni 2020, Tanggal Accepted: 29 Agustus 2020)
}

\begin{abstract}
ABSTRAK
Desa Bebidas di Kabupaten Lombok Timur merupakan salah satu destinasi wisata unggulan Pulau Lombok yang berada di kaki Gunung Rinjani. Desa ini terdampak langsung bencana gempa di tahun 2018 dan pemulihan ekonominya relatif lambat. Penyebabnya adalah kurangnya pengetahuan dan keterampilan masyarakat untuk memanfaatkan potensi sumberdaya alam dan manusia yang meliputi potensi produk hasil pertanian/perkebunan, potensi lahan pekarangan, potensi tenaga kerja masyarakat serta potensi kawasan pariwisata Taman Terasering Desa Bebidas yang terhubung dengan kawasan wisata Sembalun. Kegiatan penyuluhan ini memanfaatkan potensi tersebut dengan melibatkan peran aktif mahasiswa peserta KKN Tematik Unram tahun 2019. Tujuan kegiatan adalah pemberdayaan ekonomi melalui diversifikasi tanaman buah-buahan dan jamur tiram dan pengembangan agroindustri. Hasil usaha binaan dapat dipasarkan di kawasan wisata sehingga mempercepat kebangkitan sektor wisata Desa Bebidas sekaligus meningkatkan pendapatan keluarga petani mitra. Mitra Kegiatan Pengabdian kepada Masyarakat ini adalah Kelompok Tani Bebidas Permai di Desa Bebidas - Kecamatan Wanasaba Kabupaten Lombok Timur. Pelaksanaan kegiatan dengan metode pendekatan tindak-partisipatif (Participatory Action), meliputi tahap persiapan, tahap pengadaan bahan-bahan kegiatan pengabdian serta tahap pelatihan, praktek, dan pembinaan langsung oleh tim kegiatan pengabdian pada masyarakat. Hasil kegiatan pengabdian dapat menumbuhkan kesadaran dan motivasi bisnis masyarakat mitra serta mampu mengadopsi inovasi yang disuluhkan sehingga meningkatkan pendapatan keluarga petani secara berkelanjutan serta mendukung bangkitnya sektor pariwisata Desa Bebidas - Kecamatan Wanasaba Kabupaten Lombok Timur.
\end{abstract}

Kata Kunci: Lahan Pekarangan, Peningkatan Pendapatan, Jamur Tiram, Tanaman Buah 


\section{PENDAHULUAN}

Desa Bebidas Kecamatan Wanasaba berada di ketinggian 800 meter di atas permukaan laut dan merupakan salah satu desa di kaki Gunung Rinjani yang terdampak gempa cukup parah tahun 2018. Di bagian utara Desa Bebidas adalah kawasan Taman Nasional Gunung Rinjani yang merupakan salah satu destinasi wisata alam unggulan NTB dan nasional yang tersambung dengan Sembalun yang merupakan pusat pendakian Gunung Rinjani. Potensi wisata alam Desa Bebidas terutama Taman Wisata Terasering menjadi destinasi unggulan yang berlokasi antara jalan raya Suela dengan Sembalun.

Selain itu, Desa Bebidas merupakan desa pertanian. Lahan produktifnya seluas $61,74 \%$ dari total wilayah yang mencapai 2138 ha; terdiri dari $57,06 \%$ persawahan dan 42,94\% areal perkebunan. Potensi produksi dari sektor pertanian sangat mencukupi kebutuhan pangan penduduk namun pemulihan ekonomi mencapai tingkat minimal sama dengan sebelum bencana gempa bumi, yang terjadi pada tahun 2018, berlangsung sangat lambat. Kerusakan perumahan yang parah memerlukan biaya tinggi sehingga pendapatan dari bertani tidak bisa mencukupinya.

Lebih lanjut berdasarkan hasil observasi Tim PPM pada Januari 2019 beserta mahasiswa peserta KKN Unram diketahui bahwa Desa Bebidas memiliki potensi produktif lain yang menjadi aset masyarakat untuk percepatan peningkatan pendapatan, yakni potensi lahan pekarangan dan potensi kerja keluarga petani. Kedua jenis potensi tersebut, terutama potensi ibu rumahtangga dan kelompok usia remaja di Desa Bebidas belum produktif secara ekonomi sehingga berpotensi menjadi modal dasar pengembangan ekonomi keluarga.

Berdasarkan kondisi tersebut maka
kegiatan pengabdian diharapkan dapat
memberikan kesadaran pada masyarakat untuk
mengotimalkan pemanfaatan potensi lahan
pekarangan dan potensi sumberdaya manusia


berdampak mendukung pengembangan kawasan tersebut (Maulana, 2018).

Tujuan kegiatan pengabdian kepada masyarakat ini adalah memberi penyuluhan dan pelatihan tentang berbagai potensi produktif yang dimiliki keluarga petani yang dapat digunakan untuk pengembangan usahatani tanaman, serta melaksanakan demo pembuatan rak, budidaya jamur tiram serta, serta praktek pengembangan agroindustri jamur tiram

\section{METODE KEGIATAN}

\section{Metode Pelaksanaan Kegiatan}

Metode

pelaksanaan

kegiatan

pengabdian pada masyarakat ini dilakukan dengan tahap-tahap sebagai berikut:

1. Tahap persiapan awal meliputi pengurusan ijin pengabdian, penyusunan buku Pedoman Praktis pengembangan diversifikasi Tanaman Buah-Buahan dan Jamur Tiram serta Buku Pedoman Agroindustri Pangan olahannya.

2. Tahap pengadaan bahan-bahan kegiatan pengabdian pada masyarakat

3. Tahap pelatihan, praktek, dan pembinaan langsung oleh tim pelaksana kegiatan dengan metode pendekatan tindakpartisipatif (Participatory Action). Pendekatan tindak-partisipatif (Participatory Action) yaitu suatu bentuk pendekatan yang melibatkan kelompok sasaran pada semua tahapan yang berlangsung selama implementasi kegiatan PPM (Daniel, Darmawati dan Nieldalina. 2005 dkk).

4. Tahap evaluasi implementasi model pemberdayaan untuk perbaikan di masa yang akan datang serta untuk kepentingan pelaporan hasil kegiatan PPM.

\section{Penetapan Lokasi Kegiatan Pengabdian pada Masyarakat}

Kegiatan pengabdian ini dilakukan di Desa

Bebidas Kecamatan Wanasaba Kabupaten Lombok
Timur berdasarkan pertimbangan lokasi ini merupakan lokasi yang langsung terdampak gempa Lombok tahun 2018 dan menjadi tempat pelaksanaan KKN Tematik mahasiswa Universitas Mataram periode sejak 28 Januari 2019 selama 45 hari.

Para mahasiswa di awal masa penerjunan lebih banyak melakukan kegiatan sosial seperti gotong royong dan pembuatan papan nama dusun menggunakan pembiayaan mandiri mahasiswa. Kegiatan tersebut bukan termasuk dalam Program Kerja KKN tersebut dan cakupan masyarakat yang dilayani/dibina sangat luas. Kondisi ini mengurangi kesempatan mahasiswa melakukan program kerjanya dalam rangka memberdayakan ekonomi masyarakat binaan. Untuk menguatkan kembali kinerja mahasiswa agar mencapai target sesuai rencana program kerja maka Ketua Tim Pelaksana Kegiatan PPM yang juga berstatus sebagai Dosen Pembimbing Lapangan mahasiswa KKN di Desa Bebidas menetapkan lokasi ini juga sebagai lokasi kegiatan Pengabdian Kepada Masyarakat dari sumber dana PNBP Unram tahun 2019.

\section{HASIL DAN PEMBAHASAN}

Pelaksanaan Kegiatan Pengabdian Kepada Masyarakat Kegiatan pengabdian kepada masyarakat ini dilakukan melalui tahap persiapan, sosialisasi, tahap pelaksanaan dan tahap evaluasi kegiatan sebagai berikut: tahap persiapan, tahap penyuluhan (penyampaian materi), tahap praktek, dan evaluas kegiatan

\section{Tahap Persiapan}

Tahap persiapan dilakukan pada periode waktu/tanggal 29 Januari sampai 10 Februari 2019, meliputi kegiatan:

1. Pembentukan kelompok binaan yang terdiri dari ibu rumahtangga dan anak perempuan yang bersedia dibina dan dibuktikan dengan kehadiran selama kegiatan berlangsung. 
2. Penetapan lokasi kegiatan dan pengurusan ijin kegiatan pengabdian ke Pemerintahan Desa Bebidas

3. Penyusunan materi penyuluhan untuk budidaya jamur dan tanaman buahbuahan di lahan pekarangan serta usaha produk pangan olahan berbasis jamur tiram (agroindustri).
4. Pengadaan alat dan bahan-bahan kegiatan pengabdian pada masyarakat, yakni persiapan alat-alat untuk pembuatan rak bambu untuk budidaya. Kegiatan ini dilakukan bersama kelompok sasaran yang telah dibentuk sebelumnya.

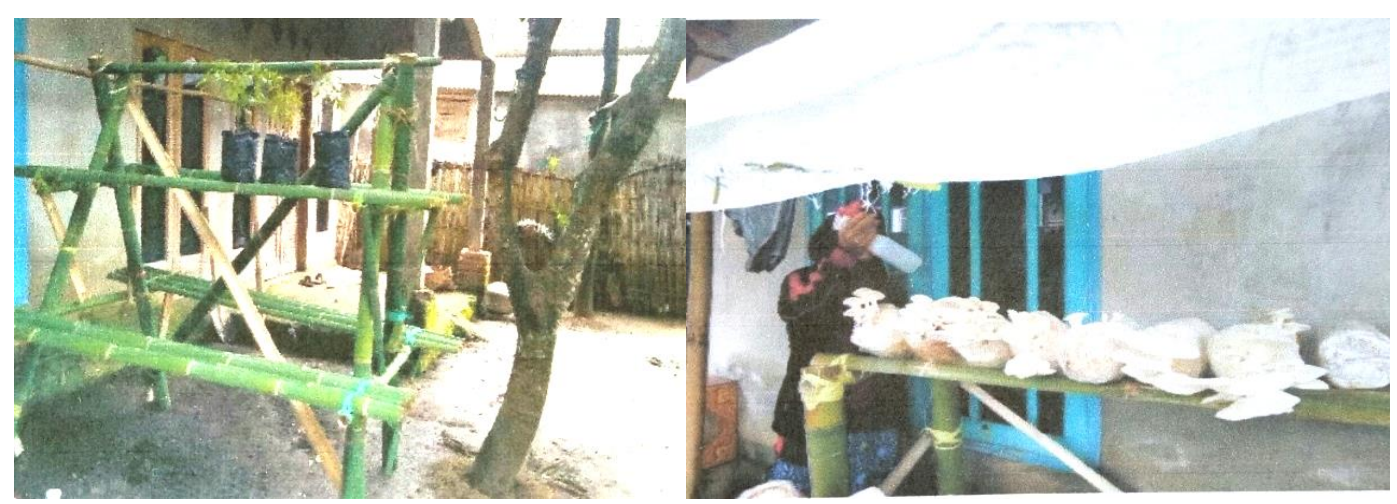

Gambar 1. Alat dan Bahan Pengabdian

Gambar 1 di atas menunjukkan bahwa bambu dan beberapa komoditi tanaman buahbuahan, yakni berupa bibit nangka dan mangga serta baglog jamur merupakan alat dan bahan yang digunakan dalam kegiatan pengabidian ini

\section{Tahap Penyuluhan}

Merupakan rangkaian aktivitas pelatihan dan penyuluhan, praktek, dan pembinaan/pendampingan langsung oleh tim pelaksana kegiatan dengan metode pendekatan tindak-partisipatif (Participatory Action) yang melibatkan kelompok sasaran pada semua tahapan kegiatan. Rangkaian aktivitas pada penyuluhan ini adalah:

1. Memberi penyuluhan untuk membangun rasa percaya diri terhadap potensi kerja dan motivasi berusaha kelompok perempuan (ibu rumahtangga dan anak remaja perempuan).

2. Memberi penyuluhan tentang potensi produktif ekonomi dari pemanfaaatan lahan pekarangan melalui diversifikasi tanaman buah-buahan dan jamur tiram dan kontribusinya terhadap perbaikan pendapatan keluarga petani.

3. Memberi penyuluhan disertai praktek tentang manfaat ekonomi kegiatan pengabdian masyarakat dan dampaknya terhadap peningkatan pendapatan keluarga. 


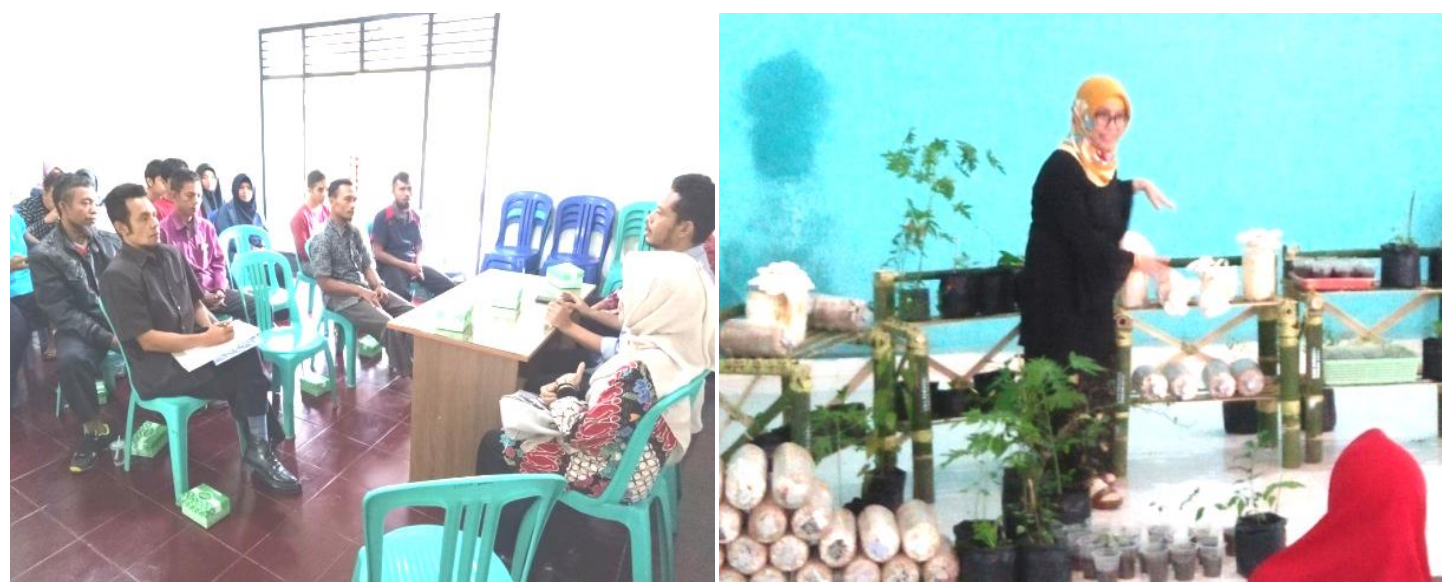

Gambar 2. Kegiatan Penyuluhan di Lokasi kegiatan

Kegiatan penyuluhan merupakan tahapan penting agar mau masyarakat memahami maksud tujuan dari diadakan kegiatan pengabdian oleh Tim Penyuluh Fakultas Pertanian Unram, serta untuk mengajak masyarakat mau berpartisipasi dalam kegiatan ini. Tanpa keterlibatan masyarakat maka dapat dikatakan bahwa pelaksanaan kegiatan pengabdian ini tidak berhasil. Oleh karena itu metode penyuluhan metode digunakan, adalah dengan tutorial disertai dengan gambar-gambar menarik agar peserta tidak bosan, lebih akrab dengan tim penyuluh, serta tertarik untuk melakukan diskusi dan tanya jawab. Materi penyuluhan yang disampaikan kepada peserta terkait manfaat lahan pekarangan sebagai sumber pangan dan sumber tambahn pendapatan keluarga, cara merawat tanaman buah-buah dan yang lebih penting cara merawat bibit jamur (baglog) supaya menghasilkan jamur tiram yang baik

\section{Kegiatan Praktek}

Setelah peserta kegiatan pengabdian memahami tentang pentingnya pemanfaatan lahan pekarang sebagai salah satu alternatif menghasilkan pangan dan pendapatan untuk keluarga, tahap berikutnya adalah kegiatan praktek. Kegiatan praktek meliputi pembuatan rak dan pemeliharaan tanaman buah-buahan dan baglog (bibit) jamur tiram.

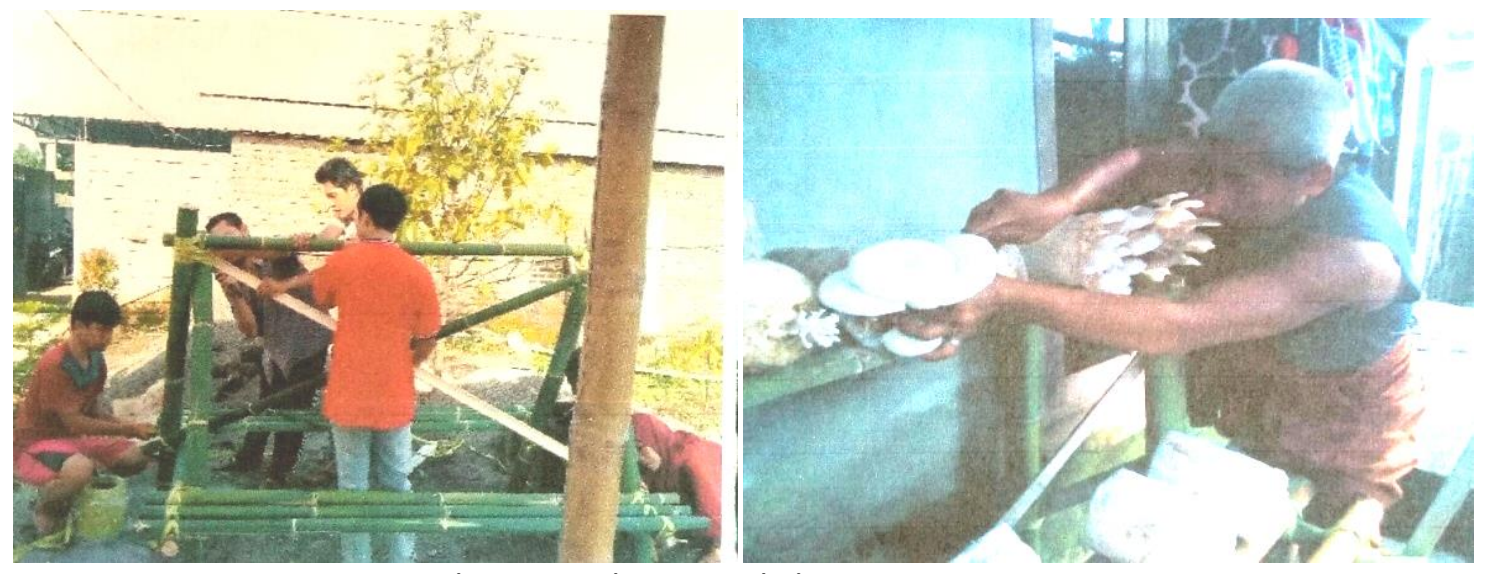

Gambar 3. Pembuatan Rak dan Perawatan Jamur

Di karenakan keterbatasan waktu maka kegiatan praktek perawatan tanaman di lahan pekarangan di fokuskan pada perawatan baglog jamur jamur tiram. Selain itu tingkat kepehaman atau pengetahuan peserta penyuluhan berkaitan dengan tanaman jamur tiram masih sangat 
terbatas. Pada kegaitan ini tim penyuluh memberikan penjelasan yang dengan disertai brosur cara merawat bibit (baglog) jamur tiram agar menghasikan jamur yang baik. Ada tiga hal yang harus diperhatikan yaitu terkait kelembaban ruangan, sirkulasi udara baik agar bibit jamur mendapatkan oksigen yang cukup serta suhu ruangan. Suhu ruangan yang baik untuk jamur tiram adalah berkisar antara 22-260 C.

Selain kegiatan perawatan jamur, tim penyuluhan juga mengenalkan praktek membuat produk-produk olahan dari jamur tiram. Setidaknya ada tiga jenis produk/pangan olahan yang bisa dihasilkan dari jamur tiram yakni sate jamur tiram, jamur krispi dan pepes jamur tiram.

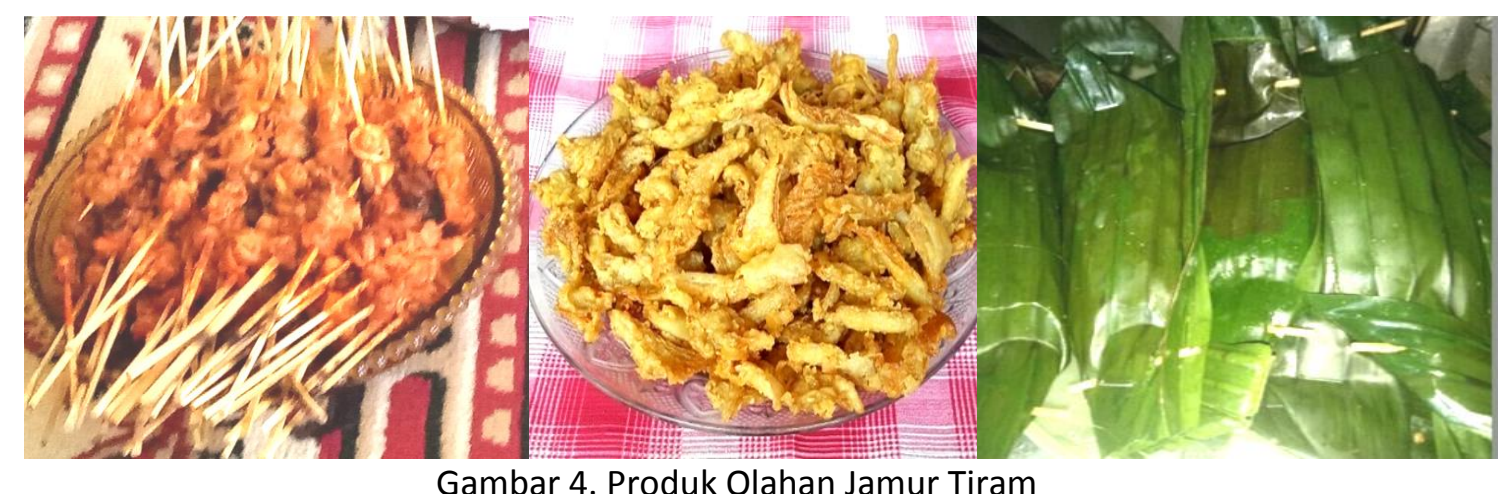

Dengan diperkenalkannya berbagai produk pangan yang bisa dihasilkan dari jamur merang ini, selain merupakan sumber pangan yang bergizi produk olahah tersebut dapat memberikan nilai tambah. Dengan demikian diharapkan para peserta penyuluhan lebih antusias dalam mengusahakan jamur tiram di lahan pekarangannya.

\section{Tahap evaluasi Kegiatan}

Kegiatan pengabdian yang dilaksanakan

oleh Tim Pengabdian Fakultas Pertanian Universitas Mataram ini berlangsung sekitar 4 mimggu, yang diawali dengan tahap persiapan dan sosialisasi, kegiatan penyuluhan dan kegiatan prakterk. Dalam pelaksanaannya, kegiatan pengabdian dirasa cukup berhasil, hal ini terlihat respon peserta sangat positif dalam mengikuti semua kegiatan yang diprogramkan, baik mulai dari penyampaian materi penyuluhan, maupun kegiatan demo dan praktek, terutama praktek pembuatan rak bambu serta kegiatan pemeliharan bibit (baglog) jamur tiram hingga menghasilkan produk jamur tiram yang baik. Dari aspek kinerja ekonominya, kegiatan ini diharapkan mampu menumbuhkan sumber pangan dam pendapatan yang baru sekaligus memberi nilai ekonomi bagi peserta penyuluhan di Desa Bebidas.

\section{KESIMPULAN DAN SARAN}

\section{Kesimpulan}

Berdasarkan hasil pelaksanaan kegiatan pengabdian masyarakat dengan "Peningkatan Pendapatan Petani Melalui Usaha Tanaman Buah Dan Jamur Tiram Di Lahan Pekarangan Masyarakat Desa Bebidas" maka dapat disimpulkan:

1. Para peserta kegiatan menunjukkan respon yang sangat positif terhadap seluruh program kegiatan mulai dari pelatihan hingga tahap proses pembuatan rak serta perawatan tanaman buah-buah dan jamur tiram.

2. Bertambahnya pengetahuan kelompok perempuan tentang: diversifikasi tanaman buah-buahan dan jamur tiram di halaman, pengetahuan tentang cara memberi nilai tambah jamur tiram segar menjadi berbagai produk pangan olahan yang bernilai ekonomi tinggi, serta pengetahuan tentang pengelolaan usaha secara komersial. 
3. Bertambahnya pengetahuan dan keterampilan masyarakat terutama peserta kegiata pengabdian tentang pengelolaan budidaya jamur tiram serta pengembangan agroindustrinya yang berpotensi sebagai sumber pangan serta pendapatan keluarga yang baru.

\section{Saran}

Berdasarkan pelaksanaan kegiatan pengabdian maka diharapkan perlunya kegiatan pengabdian lanjutan di Desa Bebidas Kecamatan Wanasaba-Kabupaten Lombok Timur untuk mendampingi kelompok perempuan binaan agar terjadi keberlanjutan pengembangan dan benarbenar memberi manfaat nyata terhadap upaya pemulihan ekonomi masyarakat pasca gempa Pulau Lombok tahun 2018.

\section{DAFTAR PUSTAKA}

Anonim. 2018. Profil Desa Bebidas Kecamatan Wanasaba - Kabupaten Lombok Timur, Propinsi Nusa Tenggara Barat. http://www.pemesbebidas.web.id

Daniel, M., Darmawati dan Nieldalina. 2005. PRA: Participatory Rural Appraisal: Pendekatan Efektif Mendukung Penerapan Penyuluhan Partisipatif dalam Upaya Percepatan Pembangunan Pertanian. Penerbit PT Bumi Aksara. Jakarta.

Dwiratna, N.P. S, dkk, 2016. Pemanfaatan Lahan Pekarangan Dengan Penerapan Konsep Kawasan Rumah Pangan Lestari. Dharmakarya: Jurnal Aplikasi Ipteks Untuk Masyarakat.

Maulana, E. 2018. Panen Jamur Tiap Hari: Panduan Lengkap Bisnis dan Budidaya Jamur Tiram. Widya Ananda. Jakarta. 